\title{
KECERDASAN EMOSIONAL PERAWAT TERHADAP KOMUNIKASI INTERPERSONAL DENGAN PASIEN
}

\author{
IGAA Sherlyna Prihandhani ${ }^{1}$, Nina Rismawati Hakim ${ }^{2}$ \\ Sekolah Tinggi Ilmu Kesehatan Bina Usada Bali ${ }^{1,2}$ \\ sherlynaprihandhani@gmail.com ${ }^{1}$
}

\begin{abstract}
ABSTRAK
Penelitian ini bertujuan untuk mengetahui hubungan kecerdasan emosional perawat terhadap komunikasi interpersonal dengan pasien di Rumah Sakit Siloam Bali. Metode penelitian ini adalah penelitian observational analytic menggunakan pendekatan cross-sectional. Hasil penelitian kepada 180 responden menggunakan teknik analisis korelasi chi square diperoleh nilai $\mathrm{p}$ value sebesar 0,001 dengan nilai $\alpha=0,05$. Simpulan, adanya hubungan yang signifikan antara kecerdasan emosional perawat dengan komunikasi interpersonal dengan pasien di Rumah Sakit Siloam Bali. Variabel yang paling berpengaruh yaitu motivasi diri, hubungan sosial dan empati serta perawat yang memiliki empati tinggi memiliki peluang 2,716 kali memiliki komunikasi interpersonal yang tinggi dibandingkan dengan perawat yang empatinya rendah.
\end{abstract}

Kata Kunci: Kecerdasan Emosi, Komunikasi Interpersonal, Perawat

\section{ABSTRACT}

This study aims to determine the relationship between nurses' emotional intelligence and interpersonal communication with patients at Siloam Hospital Bali. This research method is an observational analytic study using a cross-sectional approach. The survey results to 180 respondents using the chi-square correlation analysis technique obtained a p-value of 0.001 with a value of $\alpha=0.05$. In conclusion, there is a significant relationship between nurses' emotional intelligence and interpersonal communication with patients at Siloam Hospital Bali. The most influential variables were self-motivation, social relations, and empathy, and nurses who had high heart had 2.716 times the chance of having high interpersonal communication compared to nurses who had low heart.

Keywords: Emotional Intelligence, Interpersonal Communication, Nurse

\section{PENDAHULUAN}

Keperawatan sebagai ilmu perawatan kesehatan, berfokus pada melayani kebutuhan manusia sebagai makhluk biopsikososial dan spiritual. Praktiknya tidak hanya membutuhkan pengetahuan ilmiah, tetapi juga antar pribadi, kemampuan dan keterampilan intelektual dan teknis. Ini juga berarti terdapat komposisi pengetahuan, pekerjaan klinis dan komunikasi interpersonal (Larsen et al., 2020). Komunikasi adalah elemen penting dalam keperawatan dalam semua bidang kegiatan dan dalam semua intervensi seperti pencegahan, perawatan, terapi, rehabilitasi, pendidikan dan promosi kesehatan (Bello, 2017). Selain itu proses keperawatan sebagai metode ilmiah latihan dan implementasi keperawatan, dicapai melalui dialog, melalui lingkungan interpersonal dan dengan spesifik keterampilan komunikasi verbal (Opeyemi, 2018).

Komunikasi dapat didefinisikan sebagai pertukaran informasi, pikiran dan perasaan di antara orang-orang yang menggunakan ucapan atau cara lain. Praktik komunikasi dapat melibatkan komunikasi lisan antara pejabat kesehatan masyarakat dan perawat di satu sisi dan pasien atau kerabatnya di sisi lain. Ini adalah proses dua arah. Pasien menyampaikan ketakutan dan kekhawatiran mereka kepada perawat mereka dan membantu mereka membuat diagnosis keperawatan yang benar. Perawat mengambil informasi dan pada 
gilirannya mengirimkan informasi lain kepada pasien dengan kebijaksanaan tentang sifat penyakit dan menyarankan dengan perawatan dan rencana rehabilitasi untuk promosi kesehatan (Mahvar et al., 2020).

Komunikasi yang efektif membutuhkan pemahaman tentang pasien dan pengalaman yang mereka ungkapkan. Dibutuhkan keterampilan dan sekaligus niat tulus perawat untuk memahami apa yang menjadi perhatian pasien. Untuk memahami pasien saja tidak cukup tetapi perawat juga harus menyampaikan pesan bahwa ia dapat dimengerti dan diterima. Ini adalah refleksi dari pengetahuan para peserta, cara mereka berpikir dan merasakan dan kemampuan mereka (Lee et al., 2019). Komunikasi interpersonal antara perawat dengan pasien merupakan hal yang penting dilakukan oleh para perawat. Berdasarkan penelitian Santos bahwa lebih dari $80 \%$ waktu yang digunakan untuk berkomunikasi, $16 \%$ untuk membaca dan $4 \%$ untuk menulis. Pengembangan ketrampilan dalam komunikasi merupakan kiat yang sukses bagi seorang perawat. Waktu terbanyak yang digunakan oleh perawat adalah melakukan komunikasi dengan cara mendengar dan berbicara, maka jelas bahwa perawat harus mempunyai ketrampilan komunikasi interpersonal yang baik (Santos et al., 2019).

Kecerdasan emosi seseorang menyumbang pengaruh besar terhadap komunikasi interpersonal seseorang. Orang yang cerdas emosi akan mampu mengenali emosi, mengendalikan emosi, memotivasi diri, empati dan hubungan sosial, dengan adanya kemampuan untuk mengenali emosi, mengendalikan emosi, memotivasi diri, empati dan hubungan sosial maka akan mampu melakukan komunikasi dengan orang lain (Goleman, 2018).

Perawat yang mempunyai kecerdasan emosi yang tinggi akan mampu melakukan komunikasi interpersonal. Perawat yang mempunyai kecerdasan emosi yang tinggi akan mampu mengenali emosinya, dengan mampu mengenali emosi akan mampu mengendalikan emosi sehingga perawat akan merawat pasien dengan baik. Perawat yang cerdas emosi juga mampu memotivasi diri, mengenali emosi orang lain dan mampu melakukan hubungan dengan orang lain. Dengan kemampuannya dalam memotivasi diri, mengenali orang lain dan mampu melakukan hubungan dengan orang lain maka perawat akan mampu melakukan komunikasi interpersonal dengan pasien. Sedangkan pada perawat yang mempunyai kecerdasan emosi yang rendah maka mereka tidak mampu mengenali emosi orang lain, kurang mampu memotivasi diri dan mereka kurang mampu melakukan hubungan sosial dengan orang lain, hal ini menimbulkan perawat kurang mampu melakukan komunikasi interpersonal dengan pasien (Goleman, 2018).

Sejalan dengan penelitian yang dilakukan oleh Amini et al., (2019) menyatakan bahwa ada hubungan yang signifikan, kuat dan positif antara kecerdasan emosional dan kemampuan komunikasi pada perawat di Klinik Rawat Jalan Shiraz.

Berdasarkan hasil studi pendahuluan yang dilakukan peneliti di Rumah Sakit Siloam Bali, didapatkan hasil wawancara dengan 5 perawat pelaksana di ruang rawat inap bahwa selama ini pihak Rumah Sakit Siloam Bali belum pernah melakukan evaluasi terhadap komunikasi interpersonal yang dilakukan oleh perawat. Belum dievaluasinya komunikasi antara perawat dengan pasien tentunya berdampak pada tidak optimalnya penerapan asuhan keperawatan di ruangan.

Beberapa penelitian yang sudah pernah dilakukan oleh peneliti lain belum mengutamakan variabel kecerdasan emosional perawat dalam kaitannya dengan komunikasi interpersonal yang diterapkan perawat dalam menjalankan asuhan keperawatan kepada pasien. Namun penelitian ini lebih menekankan pada kecerdasan emosional perawat terhadap komunikasi interpersonal.

\section{METODE PENELITIAN}

Penelitian ini merupakan penelitian observational analytic dengan pendekatan cross sectional. Populasi pada penelitian ini adalah semua perawat di Rumah Sakit Siloam Bali dengan jumlah 180 perawat. Penentuan sampel menggunakan teknik pemilihan sampel, yaitu total sampling. 
Penelitian ini dilakukan pada bulan Juli 2020 - Agustus 2020. Instrument penelitian ini menggunakan kuesioner kecerdasan emosional dan kuesioner komunikasi interpersonal. Kuesioner kecerdasan emosional terdiri dari 5 variabel yang diukur yaitu kesadaran diri, pengendalian emosi, motivasi diri, empati dan hubungan sosial.

\section{HASIL PENELITIAN}

Analisis Univariat

Gambaran Kecerdasan Emosional Perawat

Tabel. 1

Distribusi Frekuensi Variabel

Kecerdasan Emosional Perawat

\begin{tabular}{lcc}
\hline Variabel & $\mathrm{f}$ & $\%$ \\
\hline Kesadaran diri & 60 & 33,3 \\
Tinggi & 120 & 66,7 \\
Rendah & 70 & 38,9 \\
\hline Pengendalian Diri & 61,1 \\
$\quad$ Tinggi & 110 & \\
Rendah & 75 & 41,7 \\
\hline Motivasi Diri & 105 & 58,3 \\
Tinggi & & \\
Rendah & 80 & 44,4 \\
Hubungan Sosial & 100 & 55,6 \\
Tinggi & & \\
Rendah & 70 & 38,9 \\
\hline Empati & 110 & 61,1 \\
Tinggi & & \\
Rendah & &
\end{tabular}

Berdasarkan tabel 1 dimensi kesadaran diri didapatkan dari 180 responden sebagian besar menyatakan rendah sebanyak 120 responden (66,7\%). 110 responden $(61,1 \%)$ pengendalian diri rendah, motivasi diri rendah sebagian besar 105 responden $(58,3 \%)$. Hubungan social sebagian besar rendah sebanyak 100 responden $(55,6 \%)$ serta empati yang rendah sebanyak 110 orang $(61,1 \%)$.

\section{Gambaran Komunikasi Interpersonal}

Tabel. 2

Distribusi Frekuensi

Komunikasi Interpersonal

\begin{tabular}{lcc}
\hline Variabel & $\mathrm{f}$ & $\%$ \\
\hline Komunikasi Interpersonal & & \\
Tinggi & 90 & 50 \\
Rendah & 90 & 50 \\
\hline
\end{tabular}

Berdasarkan tabel 2 dapat diketahui dari 180 responden, sebanyak 50\% komunikasi interpersonal perawat di Rumah Sakit Siloam Bali adalah tinggi dan rendah.

\section{Analisis Bivariat}

Tabel. 3

Hubungan Kecerdasan Emosional Perawat terhadap Komunikasi Interpersonal

\begin{tabular}{|c|c|c|c|c|c|c|}
\hline \multirow[t]{2}{*}{ Variabel } & \multicolumn{2}{|c|}{ Komunikasi Interpersonal } & \multirow[t]{2}{*}{$\mathrm{X}^{2}$} & \multirow[t]{2}{*}{$\mathrm{p}$-value } & \multirow[t]{2}{*}{ OR } & \multirow{2}{*}{$\begin{array}{c}95 \% \\
\text { CI }\end{array}$} \\
\hline & Tinggi $\mathrm{n}(\%)$ & Rendah n(\%) & & & & \\
\hline Kesadaran diri & & & 10,00 & 0,002 & 0,35 & $0,187-$ \\
\hline Tinggi & $20(22,2)$ & $40(44,4)$ & & & & 0,683 \\
\hline Rendah & $70(77,8)$ & $50(55,6)$ & & & & \\
\hline
\end{tabular}




\begin{tabular}{lcccccc}
\hline $\begin{array}{l}\text { Pengendalian Diri } \\
\text { Tinggi }\end{array}$ & $45(50)$ & $25(27,8)$ & 9,35 & 0,002 & 2,6 & $1,400-$ \\
Rendah & $45(50)$ & $65(72,2)$ & & & & 4,830 \\
\hline Motivasi Diri & & & 14,28 & $<0,0001$ & 3,25 & $1,747-$ \\
$\quad$ Tinggi & $50(55,6)$ & $25(27,8)$ & & & & 6,047 \\
$\quad$ Rendah & $40(44,4)$ & $65(72,2)$ & & & & \\
\hline Hubungan Sosial & & & 36,00 & $<0,0001$ & 7,00 & $3,609-$ \\
$\quad \begin{array}{l}\text { Tinggi } \\
\text { Rendah }\end{array}$ & $60(66,7)$ & $20(22,2)$ & & & & 13,579 \\
\hline Empati & $30(33,3)$ & $70(77,8)$ & & & & \\
$\quad$ Tinggi & $50(55,6)$ & $20(22,2)$ & & & & 8,363 \\
$\quad$ Rendah & $40(44,4)$ & $70(77,8)$ & & & & \\
\hline
\end{tabular}

Berdasarkan tabel 3 hasil analisis menggunakan uji chi-square diperoleh nilai $p$ value sebesar 0,001 dengan nilai $\alpha=0,05$, maka dapat disimpulkan bahwa ada hubungan yang signifikan antara kecerdasan emosional perawat dengan komunikasi interpersonal dengan pasien di Rumah Sakit Siloam Bali.

\section{Analisis Multivariat}

Tabel. 4

Hubungan Kecerdasan Emosional Perawat terhadap Komunikasi Interpersonal

\begin{tabular}{|c|c|c|c|c|c|c|}
\hline \multirow[t]{2}{*}{ Variabel } & \multicolumn{2}{|c|}{ Komunikasi Interpersonal } & \multirow[t]{2}{*}{$\mathrm{X}^{2}$} & \multirow[t]{2}{*}{ p-value } & \multirow[t]{2}{*}{ OR } & \multirow[t]{2}{*}{$95 \% \mathrm{CI}$} \\
\hline & $\begin{array}{c}\text { Tinggi } \\
\mathrm{n}(\%)\end{array}$ & $\begin{array}{c}\text { Rendah } \\
\mathrm{n}(\%)\end{array}$ & & & & \\
\hline Kesadaran diri & & & 10,00 & 0,002 & 0,35 & $0,187-$ \\
\hline Tinggi & $20(22,2)$ & $40(44,4)$ & & & & 0,683 \\
\hline Rendah & $70(77,8)$ & $50(55,6)$ & & & & \\
\hline Pengendalian Diri & & & 9,35 & 0,002 & 2,6 & $1,400-$ \\
\hline Tinggi & $45(50)$ & $25(27,8)$ & & & & 4,830 \\
\hline Rendah & $45(50)$ & $65(72,2)$ & & & & \\
\hline Motivasi Diri & & & 14,28 & $<0,0001$ & 3,25 & $1,747-$ \\
\hline Tinggi & $50(55,6)$ & $25(27,8)$ & & & & 6,047 \\
\hline Rendah & $40(44,4)$ & $65(72,2)$ & & & & \\
\hline Hubungan Sosial & & & 36,00 & $<0,0001$ & 7,00 & $3,609-$ \\
\hline Tinggi & $60(66,7)$ & $20(22,2)$ & & & & 13,579 \\
\hline Rendah & $30(33,3)$ & $70(77,8)$ & & & & \\
\hline Empati & & & 21,03 & $<0,0001$ & 4,37 & 2,289 \\
\hline Tinggi & $50(55,6)$ & $20(22,2)$ & & & & 8,363 \\
\hline Rendah & $40(44,4)$ & $70(77,8)$ & & & & \\
\hline
\end{tabular}

Berdasarkan tabel 4 hasil uji statistik diperoleh variabel kesadaran diri memiliki hubungan dengan komunikasi interpersonal. Terdapat 3 variabel yang paling berpengaruh yaitu motivasi diri, hubungan sosial dan empati serta perawat yang memiliki empati tinggi memiliki peluang 2,716 kali memiliki komunikasi interpersonal yang tinggi dibandingkan dengan perawat yang empatinya rendah.

\section{PEMBAHASAN}

\section{Hubungan Kecerdasan Emosional Perawat terhadap Komunikasi Interpersonal dengan Pasien}

Hasil analisis menunjukkan bahwa ada hubungan yang signifikan antara kecerdasan emosional perawat dengan komunikasi interpersonal dengan pasien di Rumah Sakit Siloam Bali. Orang yang cerdas secara emosional mampu melakukan dan membedakan antara emosi yang berbeda serta menyusun rencana yang akurat dan efektif dalam tindakan untuk merespons berbagai situasi dan skenario (Kaur \& Sharma, 2019). Goleman lebih jauh berpendapat bahwa orang yang cerdas secara emosional bisa melakukan penanganan yang efektif bagi orang lain, secara emosi dengan memanipulasi situasi, bahasa tubuh dan percakapan untuk mengelola dan mengatur emosi orang lain ke suatu arah, menguntungkan 
bagi situasi. Dalam praktiknya, kecerdasan emosional dapat menjadi kompetensi, kemampuan dan sifat kepribadian dari seorang karyawan untuk memahami, memanfaatkan, dan mengelola emosi secara efektif (Goleman, 2018; Hasani et al., 2018).

Berdasarkan hasil analisis multivariat terdapat 3 variabel yang paling berpengaruh yaitu motivasi diri, hubungan sosial dan empati. Mereka yang memiliki potensi untuk kepemimpinan dimotivasi oleh keinginan kuat untuk mencapai hanya demi prestasi. Karyawan tersebut sangat optimis, energik, bersedia untuk menemukan dan mempelajari metodologi baru, tertarik untuk mengambil risiko kalkulatif dan terpapar pada tugas kreatif, bangga dengan prestasi mereka dan acuh tak acuh terhadap penghargaan yang eksternal seperti status, status, gaji, kekuatan dll. Motivasi digabungkan dengan pengaturan sendiri dapat membantu dalam mengatasi kemunduran (Munir \& Azam, 2019).

Sebuah studi menunjukkan bahwa orang yang dapat menolak bertindak secara instan pada tahap awal memiliki kecenderungan tinggi untuk memiliki kompetensi sosial di masa depan. Kemampuan ini termasuk sikap asertif, efektifitas, dapat dipercaya, dapat diandalkan, dan percaya diri, mereka dapat mengambil inisiatif ketika melakukan pekerjaan (Geun \& Park, 2019). Motivasi sangat terkait dengan optimisme. Ini adalah keterampilan psikologis penting lainnya, optimisme didefinisikan sebagai memiliki harapan yang kuat bahwa pada akhirnya akan menjadi baik-baik saja dalam hidup, terlepas dari frustrasi dan penundaan dalam pekerjaan (Raeissi et al., 2019). Dari sudut pandang kecerdasan emosional, optimisme adalah pendekatan yang mendorong maju melawan keputusasaan dan kelesuan selama masa-masa sulit. Optimisme membayar bonus seumur hidup asalkan tentu saja itu adalah optimisme sejati (Hrefish \& Al-Hadrawi, 2020).

Empati memainkan peran penting dalam manajemen hubungan. Kualitas karyawanlah yang dapat memenangkan dukungan dan kepercayaan orang lain. Keahlian empati memungkinkan karyawan untuk memahami persepsi dan pandangan orang lain dengan lebih baik, membuat suasana kerja lebih menyenangkan dan rajin. Empati membuat adanya hubungan antara individu sehingga satu dan semua yang terlibat dan tidak ada karyawan merasa dikesampingkan dan dengan demikian, seorang karyawan yang empatik diduga menjadi karyawan yang efektif. Empati juga memainkan peran penting dalam meningkatkan kepercayaan dalam interaksi karyawan-karyawan. Empati membantu karyawan untuk memiliki pemahaman yang ditingkatkan tentang lingkungan sosial baru dan membantu mereka dengan cepat belajar dan menyesuaikan diri dengan pengaturan baru. Keterampilan empati juga membantu karyawan memiliki pendekatan optimis terhadap penyesuaian dengan lingkungan dan perkembangan baru yang menghasilkan suasana yang positif (Giménez-Espert et al., 2019).

Hubungan sosial sebagai kemampuan berhubungan dengan orang lain (Goleman, 2018). Hubungan sosial mencirikan berbagai kompetensi yang lebih luas yang paling ketat terkait dengan konsep kecerdasan sosial. Hubungan sosial yang merupakan unsur penting dari kecerdasan sosial terdiri dari yang berikut, kapasitas untuk mengekspresikan diri dalam kolaborasi sosial, kemampuan untuk merasakan dan memahami beragam kondisi sosial, pemahaman tentang peran sosial, kebiasaan dan naskah, kemampuan bermain peran sosial dan keterampilan memecahkan masalah interpersonal (Issah, 2018).

Hubungan pribadi yang baik menggambarkan kemampuan perawat untuk mengajukan pertanyaan dengan kebaikan dan memberikan informasi dengan cara yang tidak menakut-nakuti, yang menunjukkan minat, menciptakan perasaan penerimaan, tulus dan hubungan yang harmonis, terutama dalam masyarakat multikultural modern (Larsen et al., 2020). Hubungan terapeutik merupakan prasyarat penting untuk komunikasi yang efektif profesional kesehatan dan pasien agar tidak hanya untuk mengirim informasi, tetapi juga secara efektif mengatasi masalah mental pasien (Hrefish \& Al-Hadrawi, 2020).

Hasil analisis juga menunjukkan bahwa empati bermain penting dalam komunikasi interpersonal perawat dengan pasien, dimana empati tinggi memiliki peluang 2,716 kali memiliki komunikasi interpersonal yang tinggi dibandingkan dengan perawat yang empatinya rendah. Empati memberi karyawan keterampilan untuk membaca dan menyadari emosi orang. Selain itu, ditunjukkan bahwa pentingnya empati dalam bagi karyawan tidak dapat dianggap 
enteng karena empati memberi karyawan kendali dalam proses kepemimpinan dengan demikian mereka mampu membuat pilihan yang benar (Chong et al., 2020).

Singkatnya, komunikasi yang efektif tetap menjadi faktor utama dalam peningkatan hubungan interpersonal dan selanjutnya peningkatan perawatan pasien dan kualitas pemulihan pasien (Kwame \& Petrucka, 2020). Komunikasi yang efektif membutuhkan pemahaman pasien dan perasaan yang mereka ungkapkan, oleh karena itu komunikasi yang efektif menuntut keterampilan dan niat tulus perawat untuk memahami apa yang menjadi perhatian pasien (Brinderjeet, 2020). Sementara itu, Noquez (2019) berpendapat bahwa untuk memahami pasien saja tidak cukup tetapi perawat juga harus menyatakan pesan kepada pasien adalah cara yang jelas, dapat dimengerti dan dapat diterima. Seringkali, gerakan sederhana oleh pemberi perawatan seperti salam hangat dan atau pertanyaan yang bijaksana dapat membantu membuat pasien merasa nyaman dan memperkuat komunikasi, dan tindakan seperti itu tidak membutuhkan upaya besar tetapi dapat menghasilkan hasil yang signifikan. Pada akhirnya, apa yang penting untuk diingat oleh pemberi perawatan adalah bahwa semua bentuk komunikasi non-verbal menyampaikan (Abdurrahman, 2018; Sustersic et al., 2018; Beauvais et al., 2019).

\section{SIMPULAN}

Ada hubungan yang signifikan antara kecerdasan emosional perawat dengan komunikasi interpersonal dengan pasien di RS Siloam Bali. Variabel yang paling berpengaruh yaitu motivasi diri, hubungan sosial dan empati serta perawat yang memiliki empati tinggi memiliki peluang 2,716 kali memiliki komunikasi interpersonal yang tinggi dibandingkan dengan perawat yang empatinya rendah.

\section{SARAN}

Diharapkan penelitian ini dapat dijadikan bahan bacaan dan mampu menambah wawasan mahasiswa kesehatan khususnya ilmu keperawatan dalam hal ini pembahasan manjemen keperawatan dan juga sebagai bahan referensi untuk mengembangkan penelitian yang lebih mendalam mengenai manajemen keperawatan dalam hal ini kecerdasan emosional perawat dengan kemampuan komunikasi interpersonal dengan pasien di Rumah Sakit Siloam Bali

\section{DAFTAR PUSTAKA}

Abdurrahman, N. H. (2018). The Effect of Interpersonal Communication Skills and Work Motivation on Performance of Marketing Employee. International Journal of Engineering and Technology (UAE), 7(2), 190-195. https://doi.org/10.14419/ijet.v7i2.29.13314

Amini, M., Amini, M., Nabiee, P., \& Delavari, S. (2019). The Relationship Between Emotional Intelligence and Communication Skills in Healthcare Staff. Shiraz E Medical Journal, 20(4), 2018-2020. https://doi.org/10.5812/semj.80275

Beauvais, A. M., Özbaş, A. A., \& Wheeler, K. (2019). End-of-Life Psychodrama: Influencing Nursing Students' Communication Skills, Attitudes, Emotional Intelligence and Self-Reflection. Journal of Psychiatric Nursing, 10(2), 103-110. https://doi.org/10.14744/phd.2019.96636

Bello, O. (2017). Effective Communication in Nursing Practice: A Literature Review. Arcada, 5(6), 1-54. http://urn.fi/URN:NBN:fi:amk-2017053011199

Brinderjeet, K. (2020). Interpersonal Communications in Nursing Practice - Key to Quality Health Care. Archives of Nursing Practice and Care, 6, 019-022. https://doi.org/10.17352/2581-4265.000044

Chong, S. C., Falahat, M., \& Lee, Y. S. (2020). Emotional Intelligence and Job Performance of Academicians in Malaysia. International Journal of Higher Education, 19(1), 69-80. https://doi.org/10.5430/ijhe.v9n1p69 
Geun, H. G., \& Park, E. (2019). Influence of Emotional Intelligence, Communication, and Organizational Commitment on Nursing Productivity among Korean Nurses. Journal of Korean Academy of Community Health Nursing, 30(2), 226-233. https://doi.org/10.12799/jkachn.2019.30.2.226

Giménez-Espert, M. del C., Prado-Gascó, V. J., \& Valero-Moreno, S. (2019). Impact of Work Aspects on Communication, Emotional Intelligence and Empathy in Nursing. Revista Latino-Americana de Enfermagem, 27. https://doi.org/10.1590/15188345.2933.3118

Goleman, D. (2018). Emotional Intelligence, Why It Can Matter more Than IQ. In Library of Unviolent Revolution (2nd ed.). Lin

Hasani, A. M. P., Mokhtaree, M., Fathollahi, M., \& Farrokjzadian, J. (2018). Interpersonal Communication Skills and Its Association with Personality Dimensions of Nurses in Rafsanjan University of Medical Sciences, Iran, in 2015. Journal of Occupational Health and Epidemiology, 7(2), 112-118. https://doi.org/10.29252/johe.7.2.112

Hrefish, Z. A., \& Al-Hadrawi, H. H. (2020). Emotional Intelligence and Work-Related Stress among Nurses Working in Psychiatric Hospitals. Indian Journal of Forensic Medicine and Toxicology, 14(1), 1164-1168. https://doi.org/10.37506/v14/i1/2020/ijfmt/193065

Issah, M. (2018). Change Leadership: The Role of Emotional Intelligence. SAGE Open, 8(3). https://doi.org/10.1177/2158244018800910

Kaur, J., \& Sharma, A. (2019). Emotional Intelligence and Work Performance. International Journal of Recent Technology and Engineering, 8(23), 1658-1664. https://doi.org/10.35940/ijrte.B1301.0782S319

Kwame, A., \& Petrucka, P. M. (2020). Communication in Nurse-Patient Interaction in Healthcare Settings in Sub-Saharan Africa: A Scoping Review. International Journal of Africa Nursing Sciences, 12(August 2019), 100198. https://doi.org/10.1016/j.ijans.2020.100198

Larsen, R., Mangrio, E., \& Persson, K. (2020). Interpersonal Communication in Transcultural Nursing Care in India: A Descriptive Qualitative Study. Journal of Transcultural Nursing. https://doi.org/10.1177/1043659620920693

Lee, C. T., Phillips, S., Tiso, S., \& Fitzpatrick, C. (2019). Exploring Interpersonal Relationships in a Nurse-Managed Clinic and Their Impact on Clinical Outcomes. SAGE Open, 9(3). https://doi.org/10.1177/2158244019858436

Mahvar, T., Mohammadi, N., Seyedfatemi, N., \& Vedadhir, A. (2020). Interpersonal Communication among Critical Care Nurses: an Ethnographic Study. Journal of Caring Sciences, 9(1), 57-64. https://doi.org/10.34172/jcs.2020.009

Munir, M., \& Azam, R. I. (2019). Emotional Intelligence and Employee Performance: An Intervention Based Experimental Study [Journal of Business \& Economics (20756909) Emotional Intelligence and Employee Performance: An Intervention Based Experimental Study. Journal of Business \& Economics, 9(2), 1-19. https://www.researchgate.net/publication/330133322

Noquez, A. (2019). Emotional Intelligence in Nurses and Emerging Trends: An Integrative Literature Review. International Journal of Nursing, 6(1), 12-18. https://doi.org/10.15640/ijn.v6n1a2

Opeyemi, M. O. (2018). A Literature Review on Effective Communication In Nursing Practice School of Nursing Sciences, Kenyatta University, Nairobi Kenya an official Publication of Center for International Research Development. Academic Journal of Nursing and Health Education, 7(3), 1-27. http://cird.online/AJNHE/wpcontent/uploads/2018/09/Vol.7-Issue-1.pdf

Raeissi, P., Zandian, H., Mirzarahimy, T., Delavari, S., Zahirian Moghadam, T., \& Rahimi, G. (2019). Relationship Between Communication Skills and Emotional Intelligence among Nurses. Nursing Management, 26. https://doi.org/10.7748/nm.2019.e1820 
Santos, J. L. G. Dos, Copelli, F. H. da S., Balsanelli, A. P., Sarat, C. N. F., Menegaz, J. do C., Trotte, L. A. C., Stipp, M. A. C., \& Soder, R. M. (2019). Interpersonal Communication Competence among Nursing Students. Revista Latino-Americana de Enfermagem, 27, e3207. https://doi.org/10.1590/1518-8345.3226.3207

Sustersic, M., Gauchet, A., Kernou, A., Gibert, C., Foote, A., Vermorel, C., \& Bosson, J.-L. (2018). A Scale Assessing Doctor-Patient Communication in a Context of Acute Conditions Based on a Systematic Review. PLOS ONE, 13(2), e0192306 